\title{
BED UTILIZATION PATTERN AT ZAGAZIG UNIVERSITY HOSPITALS
}

\author{
Wassif S M, Ali AS, Elsharkawy GF and Elwan A \\ Community Medicine Department, Faculty of Medicine, Zagazig University
}

\begin{abstract}
Hospital beds are an important and costly resource for all health systems. Objectives: to assess the appropriateness of hospitalization days and identify risk factors associated with extra length of hospital stay. Methods: Record analysis and indepth interview with hospital managers were conducted to review hospital rates and bed management policy for different departments of Zagazig university hospitals in 2012. Then, non emergency settings in 4 selected departments were studied in a cross sectional study involved 200 patients and 108 physicians. Patients were interviewed and their bed days were assessed by using appropriateness evaluation protocol(AEP). Physicians were asked to complete a questionnaire on bed cycle and their recommendations were recorded. Results: Record analysis and indepth interview revealed considerable variability in bed occupancy pattern among various departments with overall bed occupancy rate of $67.9 \%$. In the 4 detailed studied departments, percentages of inappropriate hospital admission and stay were $19 \%$ and $59 \%$ respectively. Elective admission and being admitted for first time were the significant predictors of inappropriate admission on logistic regression. The main causes of inappropriate stay were waiting for operating room diagnostic or therapeutic procedures in patients in medical departments and persistence of symptoms or occurrence of complications in surgical departments . Poor records and lack of application of clinical guidelines are the main causes of extra length of stay from physicians' prospective. Conclusion: Optimal use of hospital beds remains a challenge at Zagazig university hospitals .So, application of standardized electronic patients records, proper inter departmental communications, proper discharge planning, in addition to planning for rehabilitative and social services are recommended.
\end{abstract}

Key words : AEP - utilization review - bed turnover.

\section{INTRODUCTION}

Tnappropriate hospitalization is an important concern. Substantial levels of unnecessary hospital use have been reported in several countries $^{(1)}$. Increasing economic pressures coupled with an expanding ageing of population1and a hostile economic climate have led to growing interest in the optimization of bed usage within hospitals ${ }^{(1)}$.

Appropriateness of setting, one dimension of quality in health care, is an assessment of concordance between the level of care a patient requires to achieve a benefit and the level of care actually received ${ }^{(2)}$

Inappropriate hospital use is defined as days a patient is hospitalized to receive care that, from the clinical perspective, could be provided on a less complex level ${ }^{(3)}$. Appropriateness means that "people get the care they need" and "they get it in the right way" (4).

Many studies attempt to identify the factors associated with inappropriate utilization of hospital resources, in an effort to explain the phenomenon. Patient-related factors include patient demographic, social, financial, functional and clinical factors. Physicians and hospitalrelated factor include absence of physician autonomy in decision making. Hospital-related items, for example, absence of clinical guidelines and Poor medical record system ${ }^{(5)}$.

As there is still a need for studies in this research area from different setting to reach evidence, this study was conducted. The aim of the study is to increase efficiency of hospitalization process through reviewing the appropriateness of setting of both hospital admission and stay.

\section{METHODS}

Data collection included two parts:

First part: Assessment of bed utilization pattern in Zagazig university hospitals in general through record analysis and in depth interview:

Record analysis: Reviewing medical records from hospital statistics unit and calculation of following indicators for the year 2012:-

- Average hospital stay= total inpatient days/ no of admissions

- Bed turnover rate $=$ no of discharges/ no of beds

- Occupancy rate = no of bed days used/ no of available bed days

Indepth interview with managers : open ended questions about bed management policy and utilization review were asked .Their opinions and recommendations were recorded.

2- Second part: Detailed studying of four departments through application of appropriateness evaluation protocol and patient opinions questionnaire in addition to health care provider questionnaire to evaluate appropriateness of hospital admission and stay:

Four departments in Zagazig University Hospitals (ZUH) were included to represent the hospital departments: general surgery\& Internal medicine as the main major specialties in addition to2 randomly selected departments; one department to present special medical departments( chest department) and the other to 
present special surgical departments(Orthopedic department ). The days of assessment of appropriateness of admission and stay using Appropriateness Evaluation Protocol (AEP) were selected randomly. Assessment was done once for each patient. As, Departments are divided into wards, patients in a randomly selected, non emergency ward were taken as a cluster (5 or 6 patient per day). Data collection was done in June 2012 till February 2013. Two months for each department.

Retrospective review of admissions and concurrent review of hospital stay through patients files with the aid of residents and nurses in charge were done.

Psychiatric and pediatric patients and patients staying in special services units (such as intensive care units, coronary care, endoscope, and dialysis center) were excluded from the study because of their different needs of care.

The required sample of patients was calculated using EPI-INFO 6 statistical package at $95 \%$ confidence level with $80 \%$ power, total inpatient days 487646(ZUH statistic unit, 2010)and percentage of inappropriate hospital days of $32.4 \%^{(6)}$ to be 200 inpatient day .So ,200 patients were included .Every patient was interviewed and his/ her bed day was assessed.

The sample of physicians was calculated according to perceived rate of inappropriate hospitalization of $39.4 \%{ }^{(5)}$, and total number of residents in Zagazig university hospitals of 380 (according to ZUH workers affaires) to be 108 physician.

The study employed appropriateness Evaluation protocol checklists (AEP) that contain two sets of criteria designed to identify inappropriate admissions and inappropriate stays. AEP are objective and independent of the diagnosis. The criteria evaluating admission and stay include 19, 27 items respectively, referring to medical and nursing care and the patient's clinical condition. If any one of these criteria are met on any given day, the stay is considered to be appropriate. AEP has documented reliability and validity ${ }^{(7)}$.

Structured questionnaire for patients: a modified Arabic translation of inpatient experience survey of national health service hospital and Picker Institute Europe ${ }^{(8)}$ was tested for validity and reliability and applied during patients interview about admission and discharge data.

Structured questionnaire for Health care providers: residents were asked to complete a questionnaire about inappropriate patients admission and stay items from their point of view.

\section{Ethical considerations:}

Required permissions and authorization were obtained. The research was approved by the research and ethics committees of the faculty and hospitals. Patients gave informed consent to participate.

\section{RESULTS}

From record analysis of year 2012, table (1) shows that there was considerable variability in bed occupancy according to specialty. Some departments are under utilized as Psychiatry and neurology. Overall bed occupancy was $67.9 \%$. Indepth interview with managers of information technology, Statistics and quality departments revealed that intensive care units and emergency wards have high bed occupancy rate and high bed turn over(over utilized) while non emergency and private (Economic treatment) wards are underutilized.

Regarding the detailed study in the internal medicine, general surgery, chest and orthopedic departments, table(2) shows that percentages of inappropriate admission and stay were $19 \%$ and $59 \%$ respectively .General surgery had high inappropriate admissions (35\%), while all admissions to orthopedic department were appropriate. All of the 4 studied departments have inappropriate stay $(>50 \%)$ with Internal medicine department having the highest inappropriate hospital days $(64 \%)$.

Table(3a) shows significant association between age, marital status and residence with inappropriate hospital admission. Also, Table (3b) indicates significant association of payment method, number and mode of admission with inappropriate admission. Out of all sociodemographic and patients hospitalization characteristics, the only significant factor for inappropriate stay was the number of admissions.

Table (4) reveals that on logistic regression analysis , mode of admission (elective admission) and being admitted for first time were the only significant predictors of inappropriate admission. Elective admission was 4.7 times associated with inappropriate admission more than admission on emergency then being transferred to non emergency sector of the department.

From patients interview data analysis, Table (5a) shows that there was significant difference between inappropriately and appropriately staying patients as regard their satisfaction with explanation of their condition $36.6 \%$ unsatisfied in appropriate group versus $51.8 \%$ in inappropriate group) Table (5b) shows that (66\%) of appropriate group were not involved in decision of discharge compared to (88.2\%) of inappropriate group. Reason of delay 
was explained to (34.2\%) of appropriate group versus $(25.4 \%)$ of inappropriately staying patients. There was significant difference between the two groups in all items of discharge planning except being told information about drugs which was deficient in both groups.

Table (6) demonstrates that the main reasons for inappropriate stay from patients prospective were waiting for an operating room therapeutic or diagnostic procedure (20.5\%)followed by persistence of symptoms $(19.2 \%)$ then the need for social or rehabilitative services $(16.4 \%)$. The first reason was found more in medical departments while the second one was mainly in surgical departments. The third one was encountered in both medical and surgical settings.

In physicians' opinions, poor quality of records, lack of application of clinical guidelines and lack of blood needed for transfusion were the main reasons for inappropriate stay (table7) $\boldsymbol{\&}$ fig1

Results of record analysis:

Table(1) Average hospital stay, bed turn over and occupancy rates in some non emergency departments in Zagazig university hospitals 2012:

\begin{tabular}{llll}
\hline Department & $\begin{array}{l}\text { Bed occupancy rate } \\
\%\end{array}$ & $\begin{array}{l}\text { Bed turnover rate } \\
\text { (Person/ bed) }\end{array}$ & $\begin{array}{l}\text { Average hospital stay ( } \\
\text { days) }\end{array}$ \\
\hline -Neurology & 29.0 & 7 & 15.2 \\
\hline -Psychiatry & 32.0 & 8.7 & 13.3 \\
\hline $\begin{array}{l}\text {-Cardiothoracic } \\
\text { surgery }\end{array}$ & 33.0 & 25.4 & 4.7 \\
\hline $\begin{array}{l}\text {-Gynecology } \\
\text { surgery }\end{array}$ & 38.0 & 15.3 & 9.2 \\
\hline -Urology & 42.0 & 24.2 & 6.4 \\
\hline -E N T & 44.0 & 76.8 & 2.1 \\
\hline -cardiology & 48.0 & 31 & 5.6 \\
\hline -General surgery & 48.0 & 27.1 & 6.5 \\
\hline -Neurosurgery & 51.0 & 20.5 & 9 \\
\hline -ophthalmology & 57.0 & 43.1 & 4.8 \\
\hline -Internal medicine & 57.0 & 61.5 & 3.4 \\
\hline -chest & 62.0 & 23.5 & 9.7 \\
\hline -Rheumatology & 64.0 & 30.2 & 7.8 \\
\hline -Orthopedic & 65.0 & 20.4 & 11.6 \\
Surgery & & & 6.7 \\
\hline -Tropical medicine & 65.0 & 35.5 & 5.1 \\
\hline Total hospitals & 67.9 & 47.1 & \\
\hline Results of cross-section & & \\
\hline
\end{tabular}

Results of cross-sectional study:

Table(2) Estimation of proportions of inappropriate bed days by Appropriateness Evaluation protocol checklists(AEP) in the selected four departments:

\begin{tabular}{llll}
\hline Departments & $\begin{array}{l}\text { No of patients } \\
(\mathbf{2 0 0})\end{array}$ & $\begin{array}{l}\text { Inappropriate } \\
\text { admission } \\
\mathbf{( 3 8 )} \\
\text { No \% }\end{array}$ & $\begin{array}{l}\text { Inappropriate stay } \\
\mathbf{( 1 1 8 )} \\
\text { No \% }\end{array}$ \\
\hline Internal medicine & 78 & $16(20.5)$ & $50(64.1)$ \\
\hline chest & 70 & $10(14.3)$ & $40(57.1)$ \\
\hline General surgery & 34 & $12(35.3)$ & $18(52.9)$ \\
\hline Orthopedic & 18 & $0(0)$ & $10(55.6)$ \\
Total & 200 & $38(19.0)$ & $118(59.0)$ \\
\hline
\end{tabular}


Table(3 a):Patient socidemographic characteristics associated with inappropriate day of hospitalization:

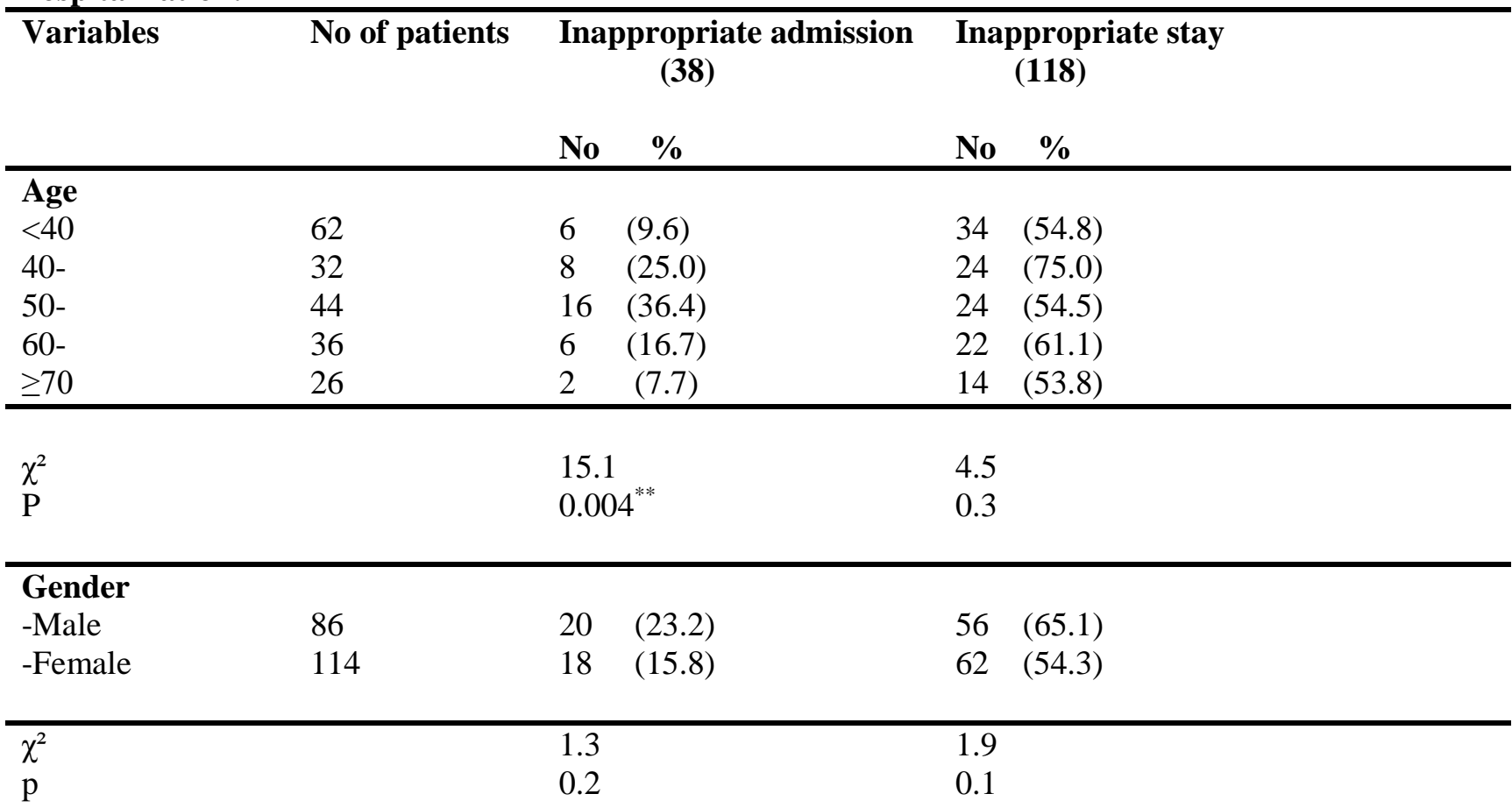

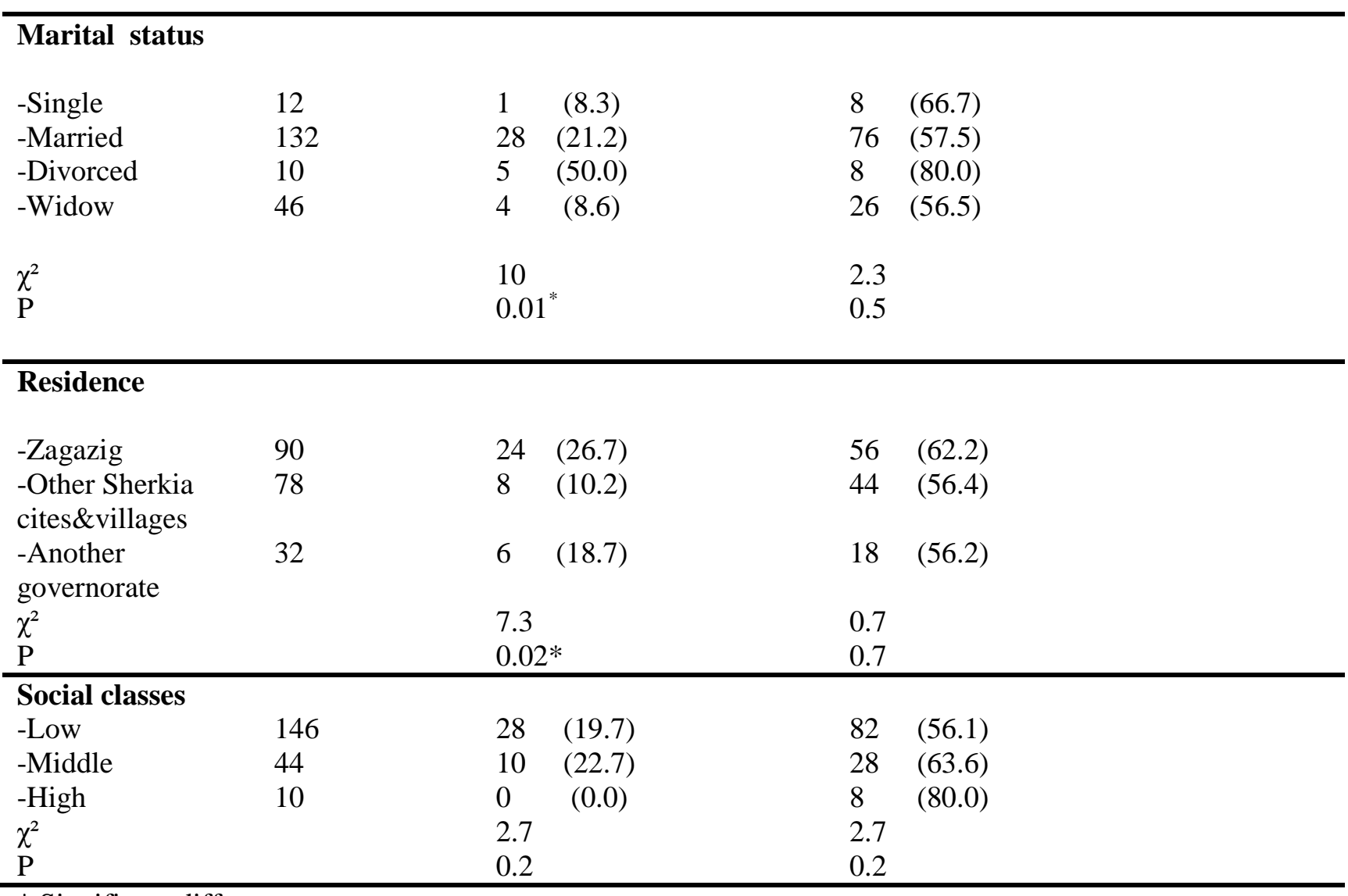

* Significant difference 
Table(3b)Patient hospitalization characteristics associated with inappropriate admission\& stay:

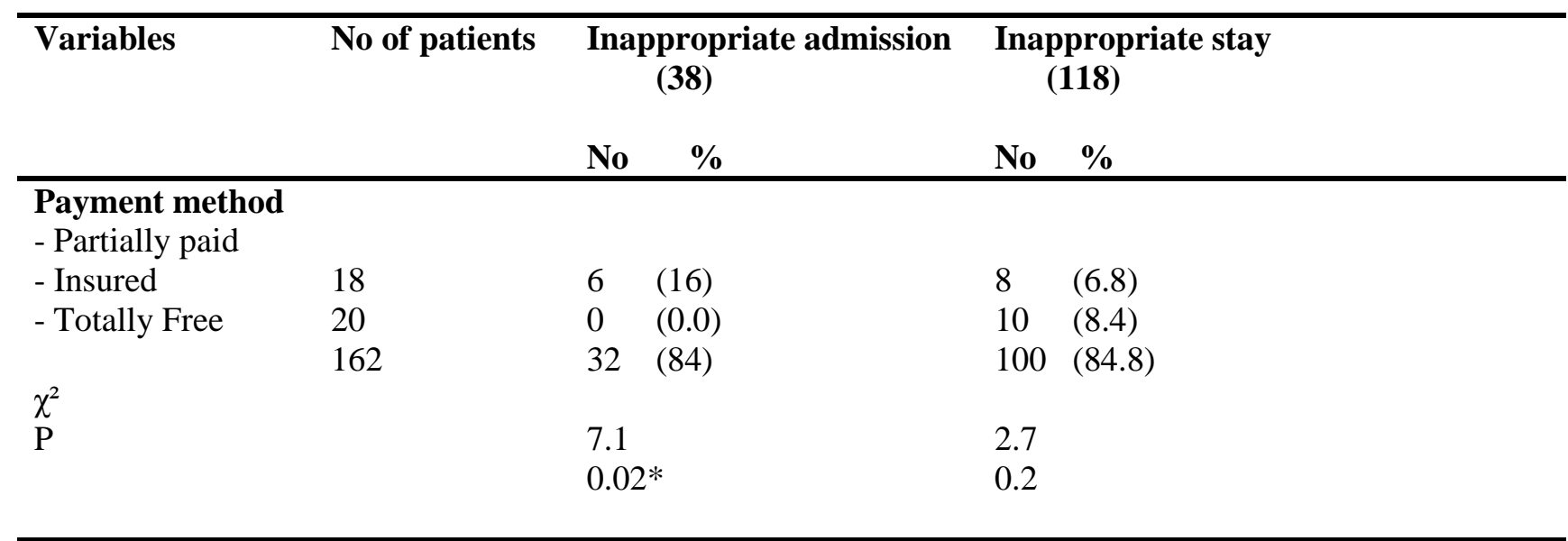

\begin{tabular}{|c|c|c|c|}
\hline \multicolumn{4}{|l|}{$\begin{array}{l}\text { Mode of } \\
\text { admission }\end{array}$} \\
\hline - Emergency room & 112 & $10 \quad(26.3)$ & $62 \quad(52.5)$ \\
\hline $\begin{array}{l}\text { - Elective } \\
\text { admission }\end{array}$ & 88 & $28 \quad(73.7)$ & $56 \quad(47.5)$ \\
\hline $\begin{array}{l}\chi^{2} \\
P\end{array}$ & & $\begin{array}{l}15.3 \text { yates } \\
0.000 * *\end{array}$ & $\begin{array}{l}1 \text { yates } \\
0.2\end{array}$ \\
\hline \multicolumn{4}{|l|}{ Length of stay } \\
\hline $\begin{array}{l}-7 \\
-14 \\
-21 \\
-28 \\
\text { More than } 28\end{array}$ & $\begin{array}{l}62 \\
74 \\
42 \\
6 \\
16\end{array}$ & $\begin{array}{ll}12 & (31.6) \\
14 & (36.8) \\
6 & (15.8) \\
2 & (5.3) \\
4 & (10.5)\end{array}$ & $\begin{array}{ll}34 & (28.8) \\
42 & (35.5) \\
26 & (22.0) \\
4 & (3.4) \\
12 & (10.2)\end{array}$ \\
\hline $\begin{array}{l}\chi^{2} \\
P\end{array}$ & & $\begin{array}{l}1.7 \\
0.7\end{array}$ & $\begin{array}{c}2.5 \\
0.6\end{array}$ \\
\hline \multicolumn{4}{|l|}{$\begin{array}{l}\text { Number of } \\
\text { admissions: }\end{array}$} \\
\hline -First admission & 96 & $26 \quad(68.4)$ & $34(28.8)$ \\
\hline $\begin{array}{l}\text {-Admitted once } \\
\text { before }\end{array}$ & 50 & $4 \quad(10.5)$ & $30(25.4)$ \\
\hline $\begin{array}{l}\text {-Recurrent } \\
\text { admissions }\end{array}$ & 54 & $\begin{array}{l}8 \quad(21.1) \\
8.6 \\
0.01^{*}\end{array}$ & $\begin{array}{l}59.6 \\
0.000^{* *}\end{array}$ \\
\hline $\begin{array}{l}\chi^{2} \\
\mathbf{P}\end{array}$ & & & \\
\hline
\end{tabular}

* Significant difference 
Table(4) Logistic regression of risk factors associated with inappropriate admission:

\begin{tabular}{lllllll}
\hline Independent variables & B & S E & Wald & Sig & $\mathbf{E x p}(\mathbf{B})$ & $\mathbf{9 5 \%}$ CI \\
\hline Age $\geq 50$ y & 0.12 & 0.3 & .0 .16 & 0.2 & 1.6 & $(0.8-3.4)$ \\
\hline $\begin{array}{l}\text { Maritalstatus(divorced or } \\
\text { widow) }\end{array}$ & -0.3 & 0.4 & 0.5 & 0.3 & 0.7 & $(0.3-1.7)$ \\
\hline $\begin{array}{l}\text { Residence(outside zagazig } \\
\text { city) }\end{array}$ & -0.8 & 0.5 & 2.5 & 0.06 & 0.4 & $(0.13-1.3)$ \\
\hline $\begin{array}{l}\text { Mode of } \\
\text { admission(elective }\end{array}$ & 1.6 & 0.4 & 16 & $0.000^{* *}$ & 4.7 & $(2.2-10.4)$ \\
$\begin{array}{l}\text { admission) } \\
\text { Payment method(free) }\end{array}$ & 0.4 & 0.4 & 1 & 0.6 & 1.3 & $(0.5-3.4)$ \\
\hline $\begin{array}{l}\text { No of admission(First } \\
\text { admission) }\end{array}$ & 0.7 & 0.3 & 5.3 & $0.01^{*}$ & 2.8 & $(1.4-7.3)$ \\
\hline Constant & -3.3 & 0.7 & 22.1 & $0.002^{* * *}$ & & \\
\hline
\end{tabular}

Table (5A) Relation between admission process and inappropriate stay from patients' interview:

\begin{tabular}{|c|c|c|c|c|c|c|c|}
\hline \multirow[t]{3}{*}{ Variables } & \multirow{3}{*}{$\begin{array}{l}\text { NO } \\
(200)\end{array}$} & \multirow[t]{3}{*}{$\%$} & \multicolumn{2}{|c|}{$\begin{array}{l}\text { Inappropriate stay } \\
\text { (118) }\end{array}$} & \multicolumn{2}{|c|}{$\begin{array}{l}\text { Appropriate } \\
\text { stay } \\
(\mathbf{8 2})\end{array}$} & \multirow[t]{3}{*}{$\mathbf{P}$} \\
\hline & & & \multirow[t]{2}{*}{ No } & \multirow[t]{2}{*}{$\%$} & & & \\
\hline & & & & & No & $\%$ & \\
\hline \multicolumn{8}{|l|}{ Admission process } \\
\hline - Emergency & 112 & 55.1 & 62 & $(52.5)$ & 50 & $(60.9)$ & $\chi^{2}=1.8$ \\
\hline - Out patient clinics & 88 & 44.9 & 56 & $(47.5)$ & 32 & $(39.1)$ & $\mathrm{p}=0.2$ \\
\hline \multicolumn{8}{|l|}{$\begin{array}{l}\text { Explanation of the } \\
\text { condition: }\end{array}$} \\
\hline -Completely & 28 & 14.0 & 8 & $(6.7)$ & 20 & (24.4) & $\chi^{2}=13 \mathrm{p}=0.001^{* *}$ \\
\hline -To some extent & 81 & 40.5 & 49 & $(41.5)$ & 32 & $(39.0)$ & \\
\hline -Never & 91 & 45.5 & 61 & $(51.8)$ & 30 & $(36.6)$ & \\
\hline \multicolumn{8}{|l|}{$\begin{array}{l}\text { Being informed about } \\
\text { admission before it: }\end{array}$} \\
\hline - enough period & 91 & 45.5 & 48 & $(40.6)$ & 43 & $(52.4)$ & $\chi^{2}=2.2$ \\
\hline - not enough period & 109 & 54.5 & 70 & $(59.4)$ & 39 & $(47.6)$ & $\mathrm{p}=0.1$ \\
\hline
\end{tabular}


Table(5B) Relation between discharge process and inappropriate stay from patients' prospective:

\begin{tabular}{llllll}
\hline Variables & No & $\%$ & $\begin{array}{l}\text { Inappropriate } \\
\text { stay(118) }\end{array}$ & $\begin{array}{l}\text { Appropriate } \\
\text { stay(82) }\end{array}$ & $\mathbf{P}$ \\
& $(200)$ & & No $\%$ & No $\%$ & \\
\hline
\end{tabular}

\begin{tabular}{|c|c|c|c|c|c|c|c|}
\hline \\
\hline & & & & & & & \\
\hline \multirow{2}{*}{\multicolumn{8}{|c|}{$\begin{array}{l}\text {-Involvement in } \\
\text { decision of } \\
\text { discharge. }\end{array}$}} \\
\hline & & & & & & & \\
\hline Yes & 42 & 20.8 & 14 & (11.8) & 28 & (34) & $\chi^{2}=13$ \\
\hline No & 158 & 79.2 & 104 & $(88.2)$ & 54 & (66) & $\mathrm{p}=0.000^{* *}$ \\
\hline
\end{tabular}

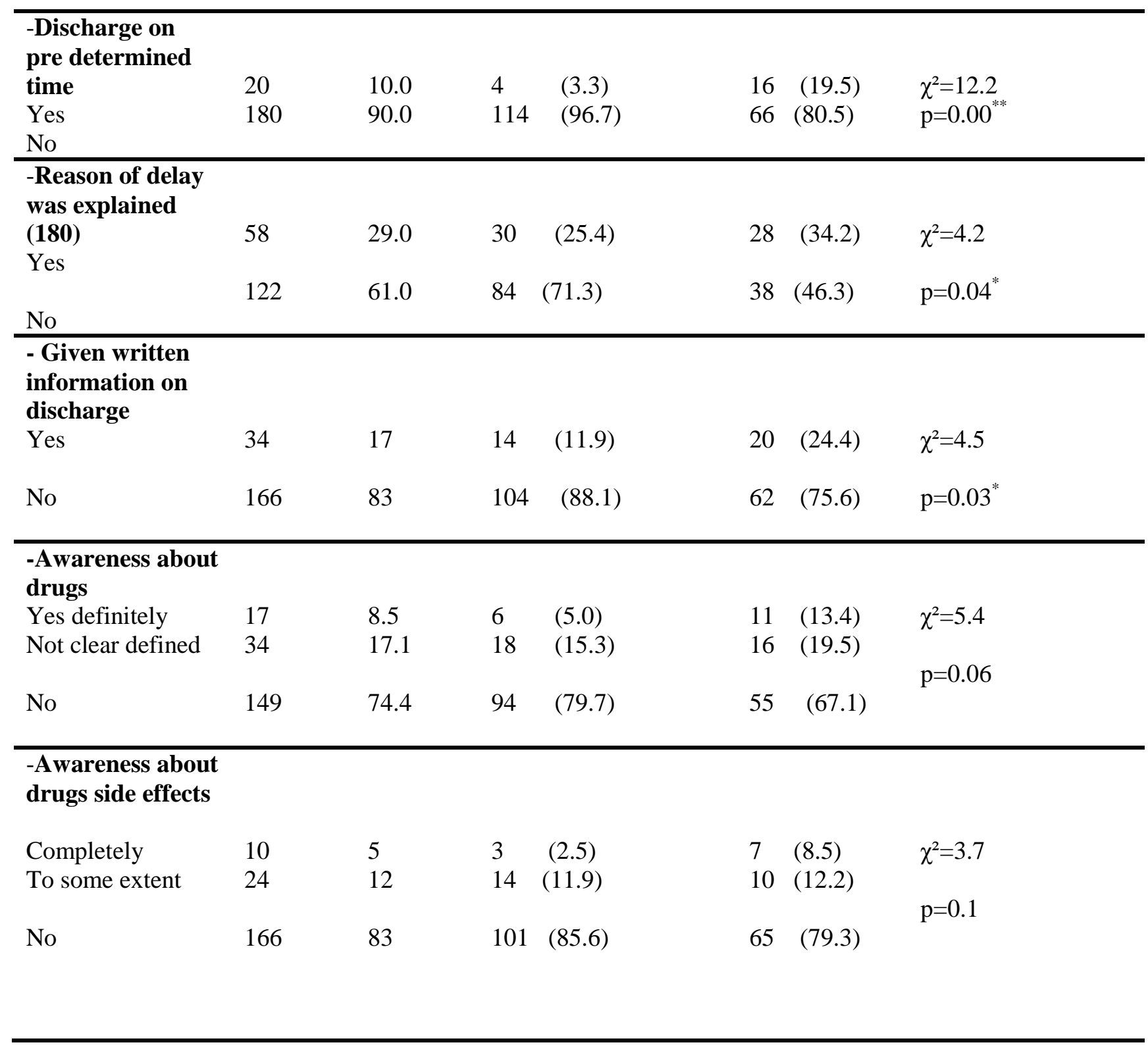


Table(6) Percent of criterion explaining inappropriate hospitalization day as expressed by patients:

\begin{tabular}{|c|c|c|c|c|c|}
\hline Variables & $\begin{array}{l}\text { Internal } \\
\text { medicine }\end{array}$ & $\begin{array}{l}\text { General } \\
\text { surgery }\end{array}$ & chest & Orthopedic & Total \\
\hline $\begin{array}{l}\text {-Unavailable type of } \\
\text { drug }\end{array}$ & 6.3 & 8.3 & 19 & 12.5 & 11 \\
\hline $\begin{array}{l}\text {-Waiting for a medical } \\
\text { opinion }\end{array}$ & 6.3 & 16.7 & 14.3 & 0 & 9.6 \\
\hline $\begin{array}{l}\text {-Occurrence of } \\
\text { complications }\end{array}$ & 0 & 25 & $\overline{0}$ & 0 & 4.2 \\
\hline $\begin{array}{l}\text {-Waiting for non - } \\
\text { operating room } \\
\text { procedure or } \\
\text { examination }\end{array}$ & 12.5 & 16.7 & 9.5 & 0 & 10.9 \\
\hline $\begin{array}{l}\text {-Waiting for an } \\
\text { operating room } \\
\text { therapeutic or diagnostic } \\
\text { procedure }\end{array}$ & 28.1 & 0 & 28.6 & 8.3 & 20.5 \\
\hline -Blood not replaced & 15.6 & 0 & 4.8 & 0 & 8.2 \\
\hline $\begin{array}{l}\text {-Need social or } \\
\text { rehabilitation service }\end{array}$ & 18.8 & 0 & 19 & 16.7 & 16.4 \\
\hline -Symptoms not relieved & 12.5 & 33.3 & 4.8 & 62.5 & 19.2 \\
\hline
\end{tabular}

Table(7)Percentage of inappropriate stay attributable to hospital management as noticed by physicians

\begin{tabular}{lll}
\hline Item & $\mathrm{N}(108)$ & $\%$ \\
\hline -Poor records & 74 & 68.5 \\
\hline $\begin{array}{l}\text {-lack of application of clinical } \\
\text { guidelines }\end{array}$ & 62 & 57.4 \\
\hline -Blood not replaced & 60 & 55.5 \\
\hline $\begin{array}{l}\text {-Absence of solid information } \\
\text { system }\end{array}$ & 35 & 32.4 \\
\hline -Poor or absent quality department & 35 & 32.4 \\
\hline -Problems with insurance system & 35 & 32.4 \\
\hline -Frequent technical errors & 35 & 32.4 \\
\hline -Bill not paid & 21 & 19.4 \\
\hline -Lengthy discharge & 11 & 10.2 \\
\hline
\end{tabular}




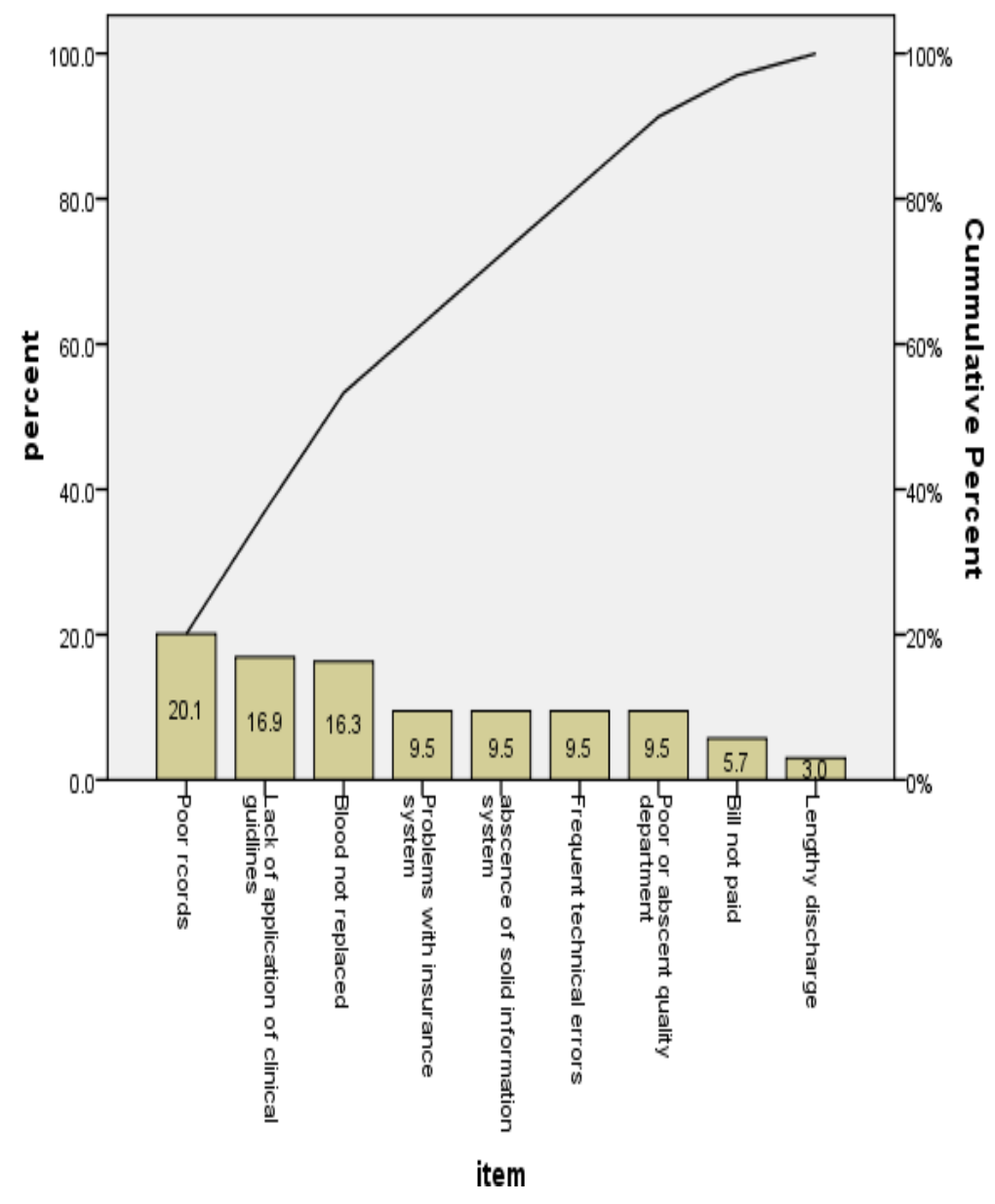

Fig(2) Pareto chart of administrative causes of inappropriate stay

\section{DISCUSSION}

The study was carried out in the University Hospital of Zagazig, a teaching and public hospital serving a total population of 6139555 $(\mathrm{MOH}, 2012)^{(9)}$. it has 2117 bed(1719 free and 398 for economic treatment). Record analysis showed that some departments were underutilized as Psychiatry departments and this can be explained by presence of stigma leading to preference of ambulatory treatment. In Neurology department, patients pay for their stay. The economic treatment hospital and departments that provide private service are still seen by the public as not prestigious and were not utilized properly.

On the other hand, in the rest of non emergency departments, the whole inpatient days are added to ICUs or emergency wards where patients were first admitted. On reading these results, we realize that actual bed occupancy is higher than the calculated. There is enough number of beds, however, a bed only contributes to health care if it is supported by an appropriate mix of staff and equipments.

On the other hand, annual bed statistics give a misleading picture of hospital capacity, so, calculation of average bed occupancy yearly is insufficient ${ }^{(10)}$. So, although $85 \%$ was used to be considered benchmarking of bed occupancy, now there is no standard optimum occupancy rate for hospitals. In the United Kingdom, the Department of Health has found that bed-occupancy rates exceeding $85 \%$ in acute care hospitals are associated with problems in handling both emergency and elective admissions ${ }^{(11)}$.

In year 2012, Zagazig university hospitals had occupancy rate $67.9 \%$ with average hospital stay 5.1 days. Among mentioned departments, neurology had the highest average hospital stay of 15.2 day followed by psychiatry (13.3) then orthopedic (11.6). Salem and Mahmoud (2008) reported a similar rate in their study at Benha University hospital where bed occupancy rate for university hospital was $(70.16 \%)$ compared to $(49.6 \%)$ for the total educational hospital $(49.62 \%)^{(12)}$.

In their study ${ }^{(12)}$, average length of hospital stay in Benha university hospital was lower(4.02days) than ours and that recorded in educational hospital (5.03 days). The highest length of stay was recorded in Orthopedic department in both hospitals. 
Saudi general hospitals have lower occupancy rates than ours, usually less than $63 \%$ level ${ }^{(13)}$. In a university hospital in Eastern Saudi Arabia, average hospital occupancy rate was of $(62.0 \%)$ together with fluctuations between departments ranging from $30.9 \%$ and $77.0 \%{ }^{(14)}$.

On the contrary to our results, in Kuwait, an analysis of bed complement in various general hospitals revealed that general surgery department in Mubarak Al-Kabir hospital has the highest bed occupancy rate $144 \%$ and Sabah hospital has the minimum Bed occupancy rate $64 \%$. Regarding internal medicine departments Amiri hospital has the maximum Bed occupancy rate (183\%) Sabah has the minimum $(112 \%)^{(15)}$. Bed occupancy rate that exceeded $100 \%$, denotes either accessory beds were used or multiple sequential admissions on the same bed per day. Some patients were admitted for few hours then were transferred or discharged. The regional variability in bed occupancy rates is contributed to number of beds, type of care and specialty.

In 2005, the average hospital bed-occupancy rate was shown to be $84 \%$ in the UK compared with $64 \%$ in the Netherlands ${ }^{(16)}$.

The occupancy rate of curative (acute) care beds stood at $76 \%$ on average across the Organization for Economic Co-operation (OECD) countries in 2009. Israel, Canada, Norway, Ireland, Switzerland, and the United Kingdom had the highest occupancy rates in $2009^{(17)}$.

In USA, bed occupancy rates was $67.8 \%$ in 2009 , ranging from $33.6 \%$ to $74 \%$ according to American Hospital Association Annual Survey (18).

As, inappropriate admission and inappropriate inpatient stay are two common measures for evaluating delivery efficiency ${ }^{(20)}$, so our study focused on these two measures.

Regarding inappropriate hospital admission, this study found a percentage of $19 \%$. This result is less than a study conducted in surgery departments in 3 general hospitals in Egypt . The rates of inappropriate admissions were $66.3 \%$ and $78.9 \%$ in the first 2 hospitals compared to $1.9 \%$ in the $3 \mathrm{rd}$ hospital that followed a specific admission protocol for elective surgery ${ }^{(21)}$.

Regarding international rates, the proportion of hospital admissions that were inappropriate were found to be between 11 and 38\% in England, 6 and 34\% in Spain 26 and 56\% in Israel, 9 and $43 \%$ in the United States , 24 and 56\% in Canada, $15 \%$ in Italy $6 \%$ in Australia ,9\% in France and $15 \%$ in Switzerland ${ }^{(22)}$.
Another study revealed that between $18 \%$ and $48 \%$ of admissions to acute care have been reported as inappropriate ${ }^{(23)}$.

Concerning the rate of inappropriate days of stay in this study, it was 59\%. This is in concordance with the upper limit found in the research of Poulas and Egar(2007) ${ }^{(23)}$. They stated that inappropriate stay in acute care ranges from around $19 \%$ to $60 \%$.

In fact, results regarding inappropriate utilization of hospital resources (over utilization and/or underutilization) were inconsistent across studies in the literature and comparisons can not be made because of different study designs, settings and populations ${ }^{(20)}$.

Regarding risk factors associated with inappropriate admission and stay as found in this study traditional person-related factors (i.e., age, marital status and residence) were significantly associated with hospitalization. Inappropriately admitted patients were old age, divorced and Zagazig dewellers more, compared to appropriately admitted.

The inappropriateness rates were higher for older age-groups due to the delays in discharging elderly patients for social reasons not specified in the clinical history or due to the higher incidence of co-morbidities in this patient group, not reflected in the AEP criteria ${ }^{(24)}$. Evaluation Protocol considers only medical reasons for hospitalization related to acute care and disregards the subjective criteria of physical, mental or social suffering which are often prominent in non acute care settings. Indeed, a medically inappropriate hospitalization can be sometimes considered appropriate for social reasons ${ }^{(7)}$. Some of these reasons are beyond the control of hospitals. Besides, the postponement of an examination or a procedure that the patient needs to another day(other than the day of review) yields unjustified day by $\mathrm{AEP}^{(7)}$.

Rodríguez et al.(2007) added that women, age older than 65 years, elective admission and stays in medical services showed the highest inappropriateness ${ }^{(24)}$. Some authors stated that their significance are often dependent on a combination with other factors such as disease type ${ }^{(25)}$.

In this study, elective admission is a significant predictor of inappropriate admission as found by logistic regression analysis. This is in agreement with a research done by Al-Tehewy and colleagues $^{(21)}$.

They found that elective admission had an odds ratio of inappropriateness 15 times that of unscheduled admission ${ }^{(21)}$. 
On the contrary to the highly significant effect of mode of admission on the inappropriate admission, it has no association with inappropriate stay neither by AEP or as got from patients interview data. Patients interview questionnaire analysis to study the effect of admission and discharge process on inappropriate stay revealed that explanation of the condition on admission decreases inappropriate stay. On the contrary, poor discharge planning is associated with more inappropriate stay. A greater proportion of patients reported inadequate discharge planning. Discharge planning is important for the overall recovery from illness/injury; it has an impact on reducing readmissions and it reduces lengths of stay $^{(26)}$.

Delayed discharges are believed to compromise the quality of patient care, reflect a lack of efficiency and effectiveness within the continuum of care as well as a lack of service coordination and is important for corrective actions to be taken by hospital administrators. ${ }^{(26)}$.

Patients in our study expressed reasons for unnecessary stay which can be associated with various organizational levels of health system. Their reasons were waiting for the results of an examination, delays for medical opnion, waiting for diagnostic procedure or treatment and gaps in the continuity from hospital care to home care.

Agreeing with previous research, inappropriate days of admission and stay in hospital are due to attending or waiting execution of diagnostic procedures ${ }^{(24)(27)}$.

On analyzing physicians responses in our study, poor records and lack of application of clinical guidelines stands for most cases of extra length of stay from physicians' point of view. This comes in concordance with a research carried out in Saudi Arabia ${ }^{(5)}$

Rodríguez et al.(2007) reported similar results. They found that the rate of unjustified days increases with lack of correct patient follow-up in the medical records ${ }^{(24)}$.

Also, pareto chart revealed that $80 \%$ of the problem is due to these areas (records, information system and clinical guidelines).

Al-Tehewy et al.( 2009) stated that system factors within the hospital are the main contributor to inappropriate admissions ${ }^{(21)}$. Attention has to be drawn to policies and practices within hospitals, which can contribute to inappropriately long hospital stays including timing of ward rounds and operating lists, radiology and laboratory services and finally holidays ${ }^{(28)}$.

\section{CONCLUSION}

Optimal use of hospital beds remains a challenge because of possible conflicts between medical needs and patients' preferences, Efforts have to be focused on interventions to reduce inappropriate admissions and hospital days. This can be approached using pre-set criteria for hospitalization redesigning the processes using quality improvement projects and utilization review programs. ALSO, Proper communication between primary and secondary care clinicians to avoid unnecessary hospitalizations. Planing for provision of social and rehabilitative services with social and voluntary work organization. should be addressed. Standardized medical records carrying patient national ID to ensure easy retrieval of information. Finally, discharge planning including giving patients written information to avoid readmissions.

\section{LIMITATION OF THE STUDY}

In AEP, the day for providing IV fluids would normally qualify as an appropriate day. For a particular patient, however, the reviewer may feel that IV fluid therapy was prolonged, and that on the particular day in question, IV fluids were not necessary.

\section{REFERENCES}

1-Scott IA(2010): Public hospital bed crisis: too few or too misused? Aust Health Rev. Aug;34(3):317-24. Available www.ncbi.nlm.nih.gov/pubmed/20797364.

Accessed on August 2013.

2- TreriseB, Dodek P, Leung A and Spinelli J(2001): under utilization of acute care settings in a tertiary care hospital . international journal for quality in health care; 13 (1): 27-32 Available at www.ncbi.nlm.nih.gov/pubmed/11330440.

Accessed on August 2013

3-Pedro A, Salvador P, Jesús M, Rafael C, Antonio C, Edith L, and Vicenta R (2007): Effectiveness of a physician oriented feedback intervention on inappropriate hospital stay.J Epidemiol Community Health.; 61(2): 128 Available at http://www.ncbi.nlm.nih.gov/pmc/articles/PMC246 5655/ Accessed on July 2012

4-Solayappan A, Jayakrishnan J and Velmani S(2011) Quality Measurement for Hospital Services 3rd International Conference on Information and Financial Engineering IPEDR vol.12 (2011) (C) (2011) IACSIT Press, Singapore Available at www.ipedr.com/vol12/44-C111.pdf. Accessed on October 2012.

5- Al-Omar B and Al-Ghanim S (2010): "Utilization of hospital resources: a survey-based study of Saudi hospitals in Riyadh City", Clinical Governance Journal; 15 (2):134 - 141. available at http://www.emeraldinsight.com/journals.htm?articl eid=1858306\&show=pdf. Accessed on May 2013

6-Ricolleau PC, Hamidou M, Lombrail P and Moret L(2009):Appropriateness of days of hospitalization: 
a comparative study at Nantes University Hospital.Presse Med.;38(4):541-50. Available at http://www.ncbi.nlm.nih.gov/pubmed/18845417. Accessed on june 2013.

7- Fontainea P, Jacques Jb, Gillain D, Sermeus Wc, Kolha $\mathrm{P}$ and Gillet $\mathrm{P}(2011)$ : Assessing the causes inducing lengthening of hospital stays by means of the Appropriateness Evaluation Protocol. Health Policy; 99,66-71 Available at www.ncbi.nlm.nih.gov/pubmed/20691493

Accessed on june 2013.

8- National Health System (2013): Inpatient survey question bank for local use_v4, Picker Institute Europe. Available at http://www.nhssurveys.org/Filestore//Inpatient_201 3/IP13_Core_Questionnaire_v1.pdf Accessed on August 2013.

9-MOH (2012): Sherkia Beds and population census. Information center, Egypt.

10-Kuntz L, Scholtes S and Vera A.(2007): Incorporating efficiency in hospital-capacity planning in Germany. Eur J Health Econ ; 8: 21323. Available at www.ncbi.nlm.nih.gov/pubmed/17216425. Accessed on May 2013

11-Keegan AD(2010): Hospital bed occupancy: more than queuing for a bed.Med J ;193(5):291-3.

12-Salem S and Mahmoud SM(2008):Hospital bed utilization in both Benha University hospital and Benha educational hospital. Benha M. J; 25 (2).

13-MOH (2002):"Health Statistical Year Book" Ministry of Health, Saudi Arabia.

14-Nour El Din M(2006):Bed Utilization fluctuations at a university hospital in Eastern Saudi Arabia and their impact on hospital cost.The Journal of the Egyptian Public Health Association (JEPHAss.) ;81 ( $1 \& 2$ ) . Available at www.epha.eg.net/new-pdf/drmostafaBed_utilization\%5B1\%5D.pdf. Accessed on August 2013.

15-AlAzmi S and Hanafi M(2006): Bed utilization indices in the general hospitals in state of Kuwait 2004 Bull. Alex.Fac.Med;42 (3).Available at www.med.alexu.edu.eg/journal/index.php/bulletin/a rticle/download/.../279. Accessed on August 2013.

16-Orendi J(2008):Health-care organization, hospitalbed occupancy, and MRSA. Lancet; 371: 14011402.

17-Organization For Economic Co- operation and Development (OECD)(2011):Health at a Glance 2011: OECD Indicators. Available at

www.oecdilibrary.org/sites/health_glance2011.../index.html. Accessed on August 2013.

18-American Hospital Association Annual Survey of Hospitals(2011): Hospital Statistics, 1976, 1981, 1991-2011 editions. Chicago, IL.

Available at

www.cdc.gov/nchs/data/hus/2011/116.pdf. Accessed on August 2013.
20- Chiu HC, Lee L J, Hsieh HM and Mau LW(2003):Inappropriate hospital utilization for long stay patients in Southern Taiwan. Kaohsiung J Med Sci;19:225-32

21- Al-Tehewy M, Shehad 1 M, Al Gaafary 1 M, AlHoussiny 1 D Nabih 1 and B Salem(2009): Appropriateness of hospital admissions in general hospitals in Egypt. East Mediterr Health J. ;15(5):1126-34. Available at www.ncbi.nlm.nih.gov/pubmed/20214126. Accessed on May 2012.

22- Teke K, Kisa A, Demir C, and Ersoy $\mathrm{K}(2004)$ :Appropriateness of Admission and Length of Stay in a Turkish Military Hospital,Journal of Medical Systems; 28( 6).Available at www.ncbi.nlm.nih.gov/pubmed/15615293. Accessed on June 2013.

23- Poulos C G and Eagar K(2007): Determining appropriateness for rehabilitation or other subacute care: is there a role for utilization review? Australia and New Zealand Health Policy; 4:(3). Available at www.ncbi.nlm.nih.gov/pubmed/17352832.

Accessed on June 2012.

24-Rodríguez FC, Morón Ide L, Martínez AD, Rodríguez LL, Lucena FM and Fernández MT(2007): Appropriateness of hospital stays in a pulmonology department. Arch Bronconeumol ;43(8):439-44.

25-Muenchberger $\mathrm{H}$ and Kendall E (2012): Determinants of avoidable hospitalization in chronic disease: Development of a predictor matrix

Centre for National Research on Disability and Rehabilitation, Griffith Institute of Health and Medical Research . Available at http://www.gpqld.com.au/content/Document/3\%20 Programs/Collaborative\%20Research $\% 20 \mathrm{Hub} / \mathrm{Hos}$ pital\%20Avoidance\%20Review\%20Paper_FINAL. pdf. Accessed on June 2013.

26-Santaella MA(2010): From bed-blocking to delayed discharges: precursors and interpretations of a contested concept Health Serv Manage Res ; 23 ( 3 ):121-127

27-Capalbo G, D'Andrea G, Volpe M, Cambieri A, Cicchetti A \& Ricciardi G. (2004): Appropriateness evaluation of short hospital admissions using Appropriateness Evaluation Protocol (Italian version): experience of a teaching hospital. Ann Ig. Nov-Dec;16(6):759-65.Available www.ncbi.nlm.nih.gov/pubmed/15697006. Accessed on August 2012.

28-Goulding L ,Adamson J , WattI, and WrightJ(2011): Patient safety in patients who occupy beds on clinically inappropriate wards: a qualitative interview study with NHS staff. BMJ Qual Saf -000280 Available at www.ncbi.nlm.nih.gov/pubmed/22101102.

Accessed on October

2012 